\title{
E-CARDS DOWNLOAD
}

\author{
K Rabiyathul Basaria ${ }^{1}$ and S Sujitha ${ }^{2}$ K Nambi Natchiar ${ }^{3}$ \\ ${ }^{1}$ Department of Computer Applications, Francis Xavier Engineering College \\ ${ }^{2}$ Department of Computer Applications, Francis Xavier Engineering College \\ ${ }^{3}$ Department of Computer Applications, Francis Xavier Engineering College
}

\begin{abstract}
This "E-Card Downloading application" is to design and develop for well secured dynamic application used for easy retrieval of necessary cards. Issued in the form of a standardized application, which includes the details like Driving license, Voter Id, Ration Card and Aadhar Card. Sometimes we come across the need of submitting or to show the proof of hardware copy of cards at this time this e-card application which is an safest application used for downloading cards of our necessary. This application also contains OTP generation in which the otp is send to the registered mail id so that we can protect our details from others.
\end{abstract}

\section{KEYWORDS}

Smart card, otp, verification,download

\section{INTRODUCTION}

The main objective of the web application is to download all the four cards in one web application. In this web application user can download all these four cards Aadhar card, Driving licence, Ration card and Voter id through unique identity number. User can also contact the admin through chatbox for seeking help. card application is considered as an easy and safest downloading methods of an cards. E-card application helps people to download regarding cards of their own necessary. It also need less manpower to handle updating details of every citizens of the country. The usage of smart card is very popular in the world. Some institutions use smart card to support their business for example, identity card, stored digital money. This paper proposed design multi purpose smart card to create identity card and payment transactions. The design make smart card doesn't save some data directly in the smart card but in the server for account based system. Authentication process must be fast to serve many transactions on client. payment card, the smart card has a microprocessor or memory chip embedded in it that, when coupled with a reader, has the processing power to serve many different applications. As an access-control device, smart cards can be used to access server. Through their combination of portability and security, smart cards are playing an increasingly important role in the rapidly developing areas of electronic commerce and online information services. Smart card technology has advanced over the last 30 years: storage and processing capabilities are improved, security has been enhanced, the management software has matured, contactless technologies are available, and multiple applications are there.Aarti Bhosale, Shweta Bhor, Pratima Sabale, Pushpak Shinde, "Survey on Smart Ration Card using Internet of Things" International Journal of Computer Applications (0975 - 8887) Volume 180 - No.3, December 2017.Dr. Satyam Pincha, Kusum Lata Joriya, "Analytical Study on Aadhaar Card (UIDAI) and its inclusion into Public Services Delivery" Journal for Studies in Management and Planning 
.Fernandes e Fizardo, Mr. Chavan Nehal Sadguru, Mr. Usapkar Yatin Digamber Mr. Naik Swaraj Shankar,Miss. Raikar Ashma Kishor, "Smart License Card" IJSTE - International Journal of Science Technology \& Engineering Volume 3 Issue 07 JanuaryMala, A. Ashwini, J. Jayapratha, E. Vimala, "A Smart Driving License System in RTO Using Quantum Machine Learning Techniques" International Journal of Engineering Research \& Technology (IJERT).Lakshmi, R. Karthikamani, N. Divya, "Aadhar Card based smart e-voting system" International Journal of Engineering and Advanced Technology (IJEAT) ISSN: 2249 - 8958, Volume-8, Issue-2S, December 2018

\section{Problem Statement}

\section{Architecture diagram}

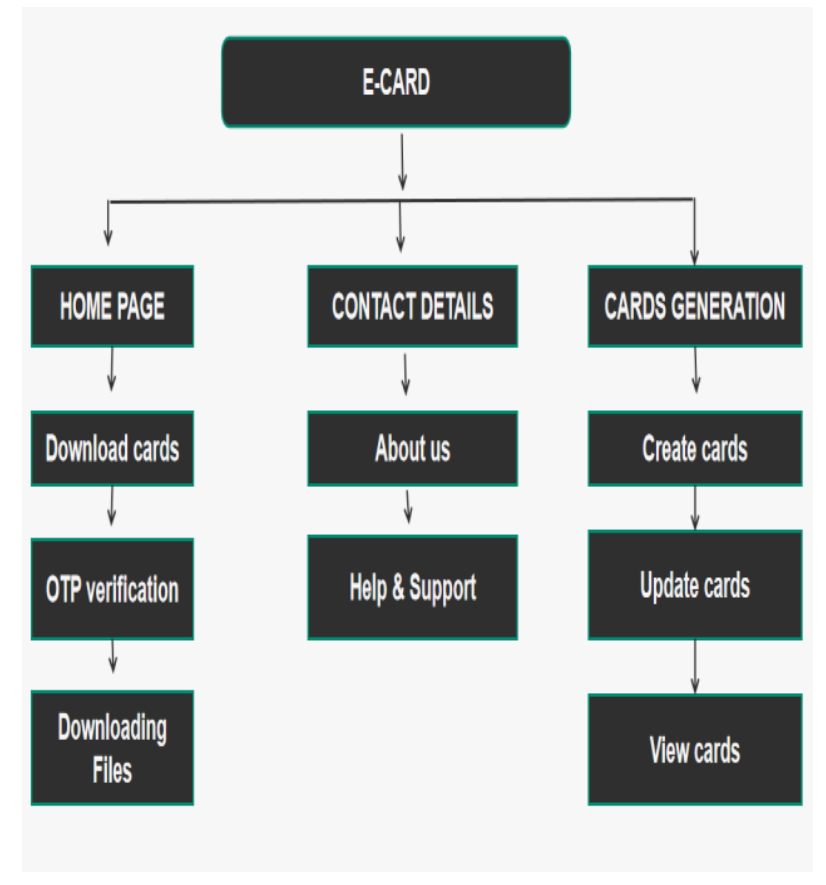

Figure 1 Architecture diagram

\section{EXPERIMENT AND RESULTS}

\section{A. Modules}

i. Cards Generation (Admin) : E-card application is an web based application used for downloading cards. In this modules we can create e-card, update e-card details like uploading aadhar card, driving licence, ration card and voter id files which to be download, view e-cards and store data

ii. My Card : In this module user can download the regarding cards of their need. In this module it contains an unique identity number for downloading each cards. It contains an captcha and otp generation through which an citizen can safely download the document file. And user can chat with the admin through chatbot.

iii. Create E-card : In this module admin can create all the details of the citizen through which they can download the regarding cards through "My card" module. 
iv. Update E-card : In this module admin can update all the cards of the citizen so that they can avoid the cards downloading of wrong details or expired cards

v. View E-cards : In this module admin can view all the card details.

\section{B. Output Screen}

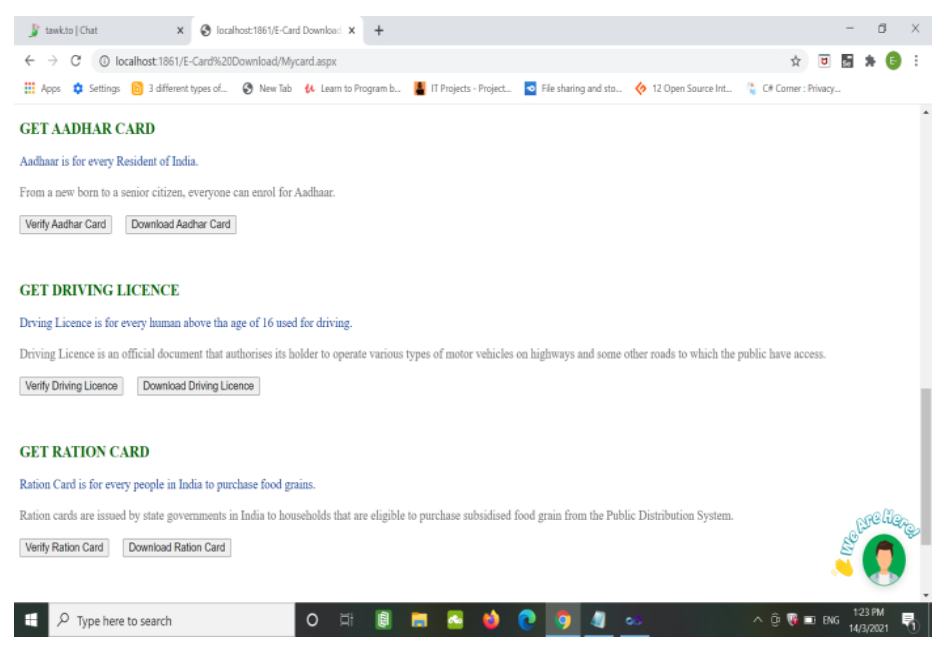

Figure1.Welcome Page

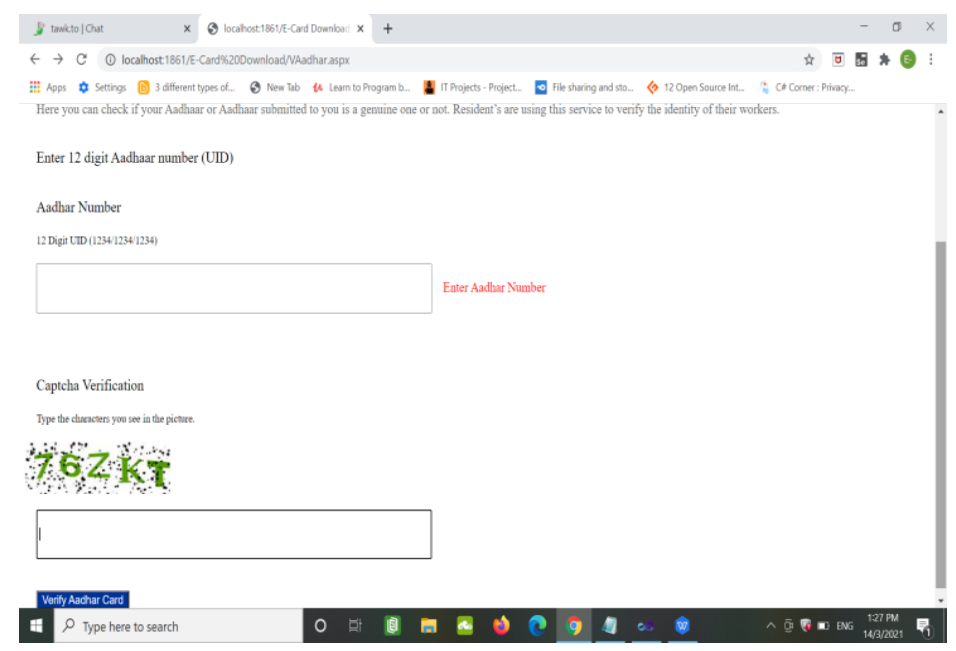

Figure 2. Verification Page 


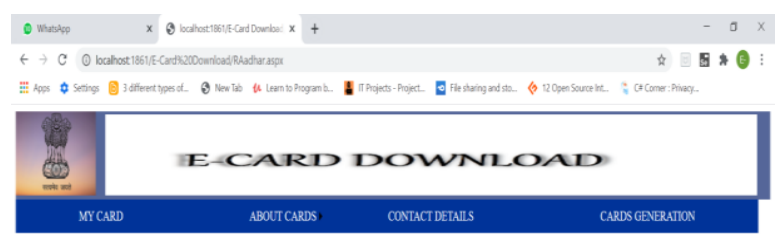

Aadhar Verification Completed:

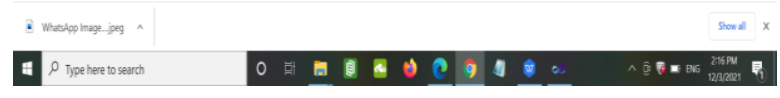

Figure 3. Verified Page

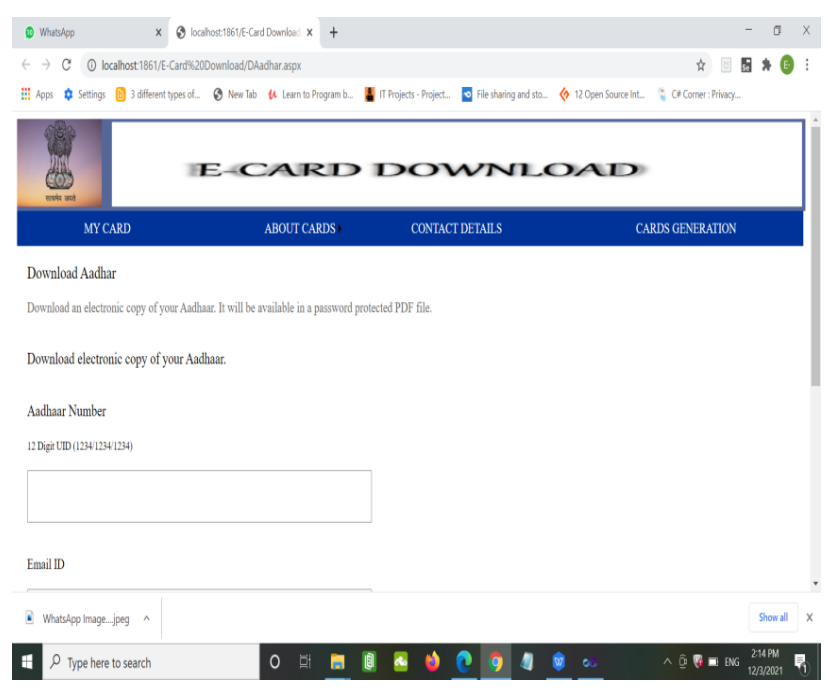

Figure 4. Download Page

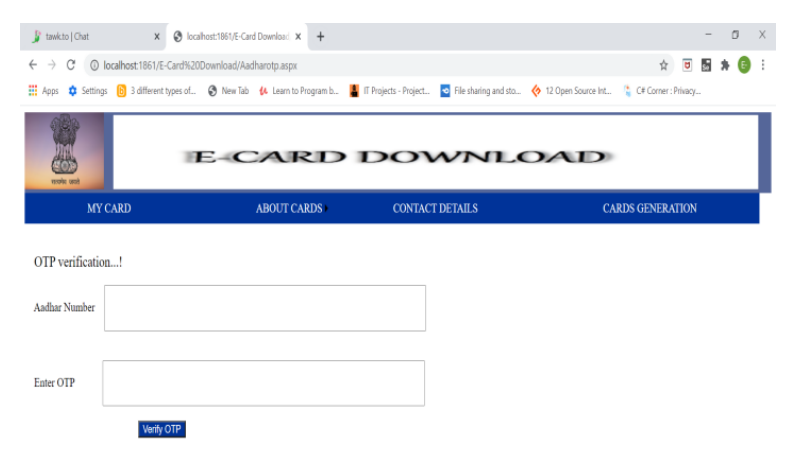

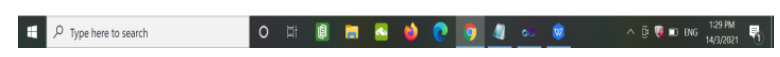

Figure 5. OTP Verification 


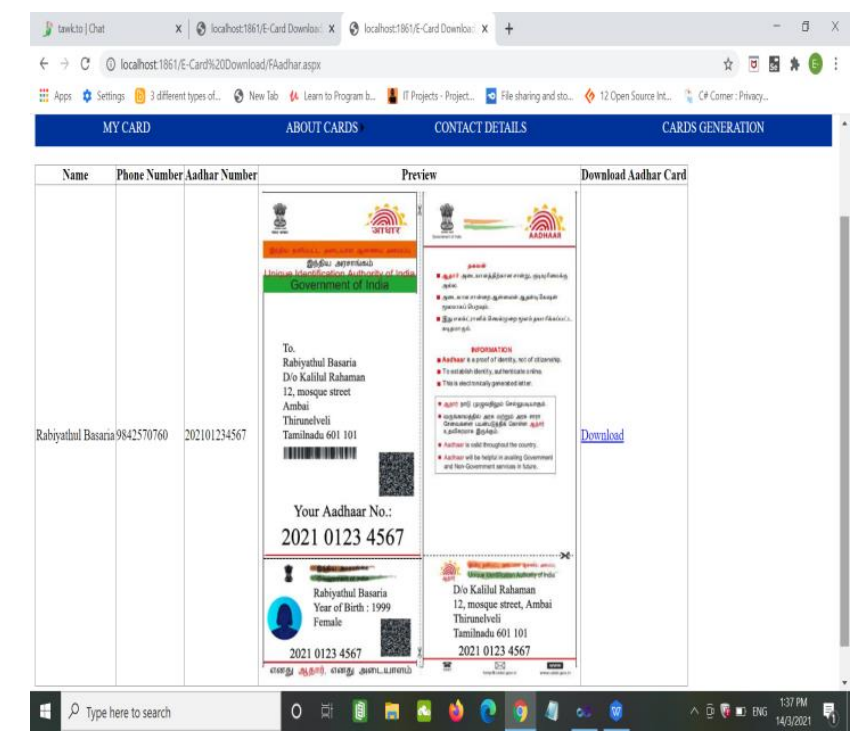

Figure 6. Desktop

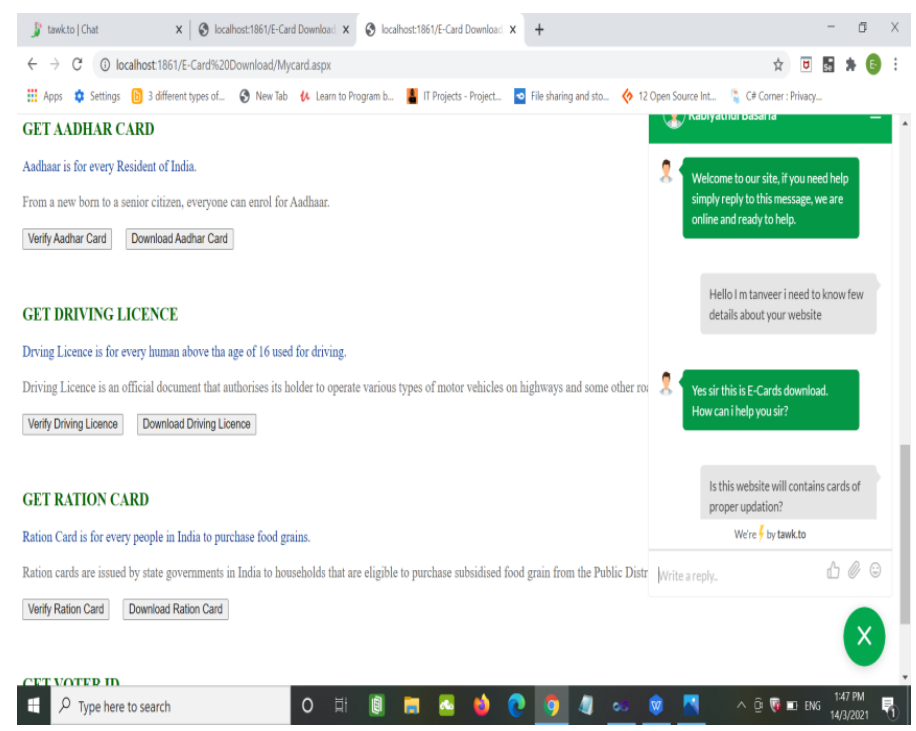

Figure 7. User chatbot 


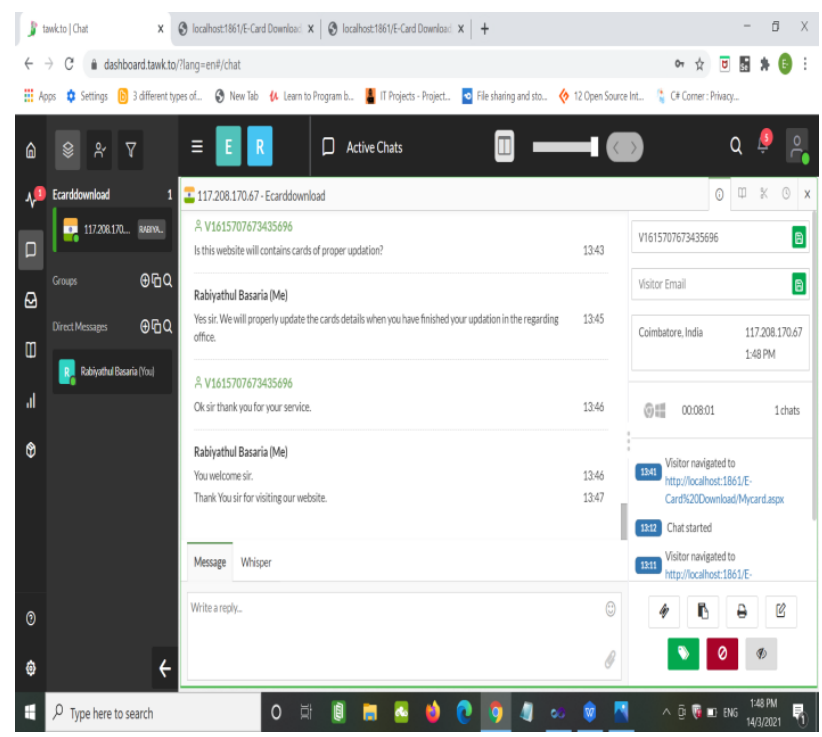

Figure 8. Admin Chatbot

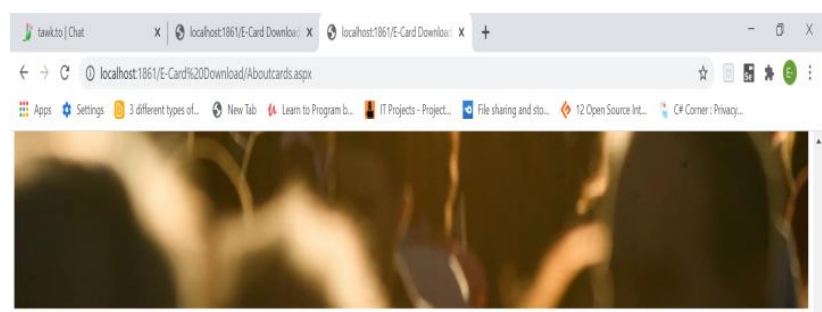

E-CARDS Download

This E.crad apolicaton is used for downloading cards of our neecessan. Through this E. card application we can download Aadhar card, Ration card, Driving licence and Voter ID through online mode We can download the cards of our own puppose Sonetmes we come a coos an need of submiting or to show the hardware proof of the cards like Aadha Card, Ration card, Diving Licence and Voter ID. At this time we can easily download our regarding cards through this sppicicton.

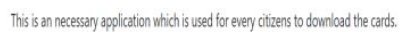

This E-crad applicaton is an combination of cards to be download. In this one application

we can downlosd four inportant cards which is used in our daly life. This sppicicton is

safest appliction which safely contains detalis of every ctitizen. This contains OTP

generation in which the otp is send to the registered mall id 50 that we can protetct our

detais trom others.

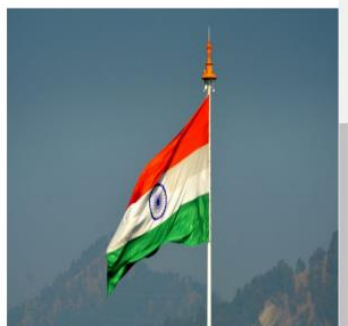

4. $P$ Type here to search

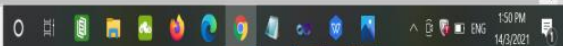

Figure 9. About Card Page 


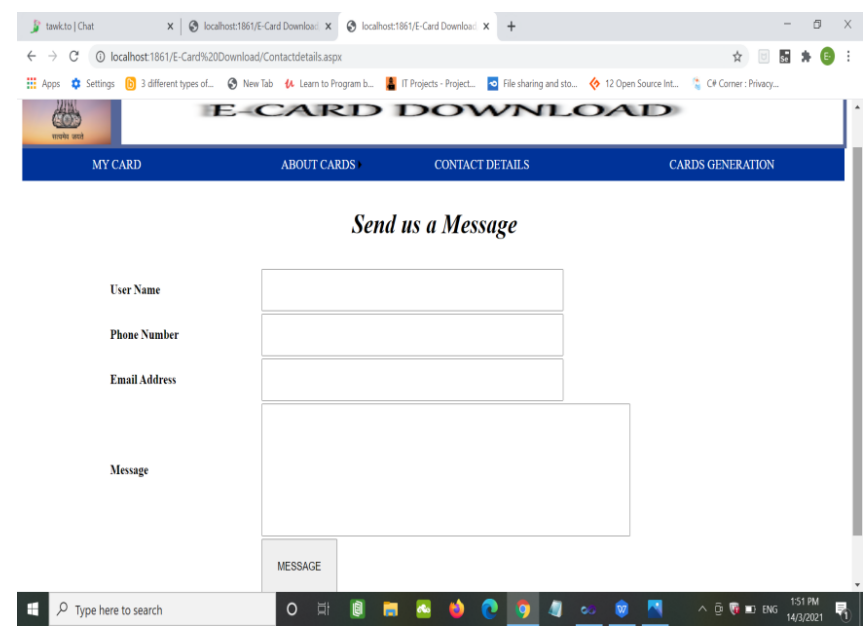

Figure 10. Contact Page
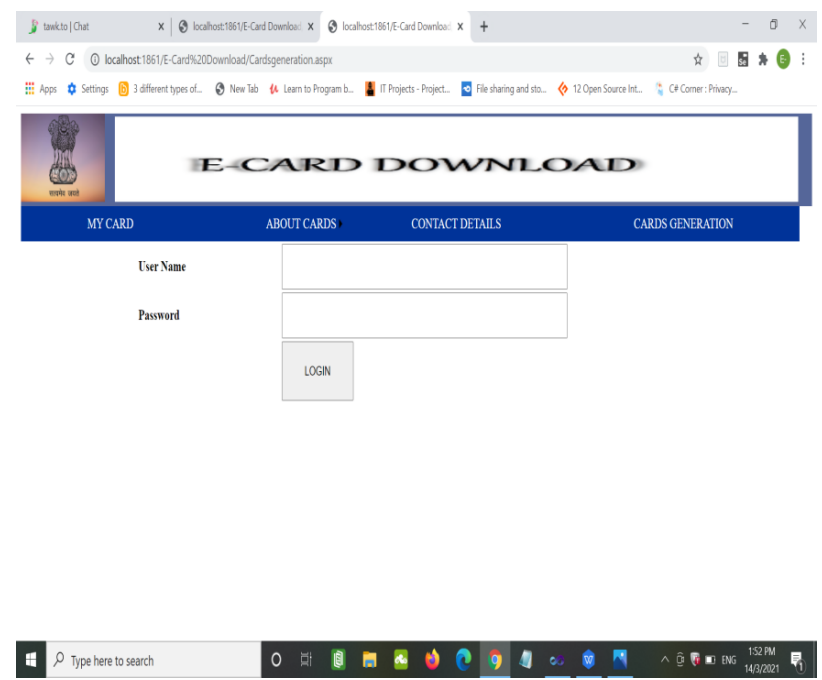

Figure 11. Cards Generation Page

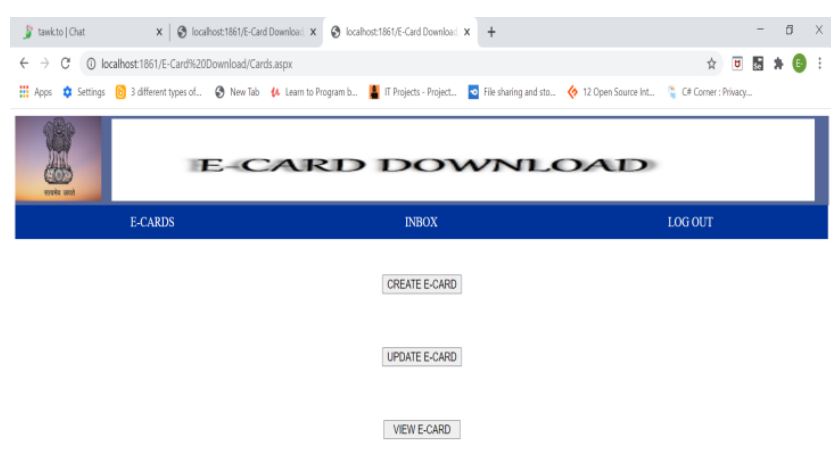

- 0 Tpe heere toserch

Figure 12. E-card page 


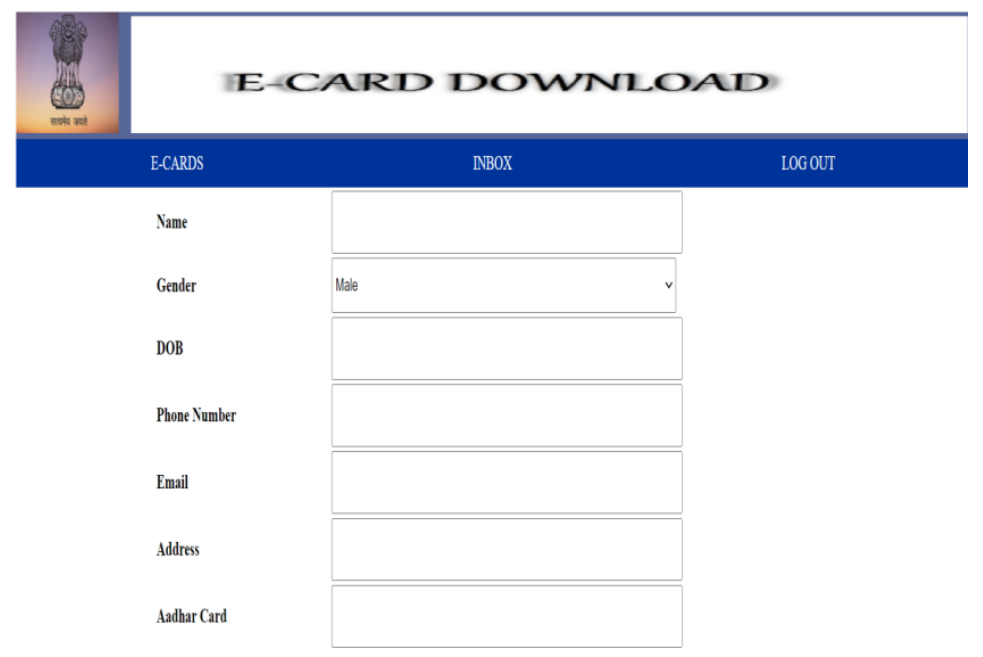

Figure 13. E-cards Registration Page

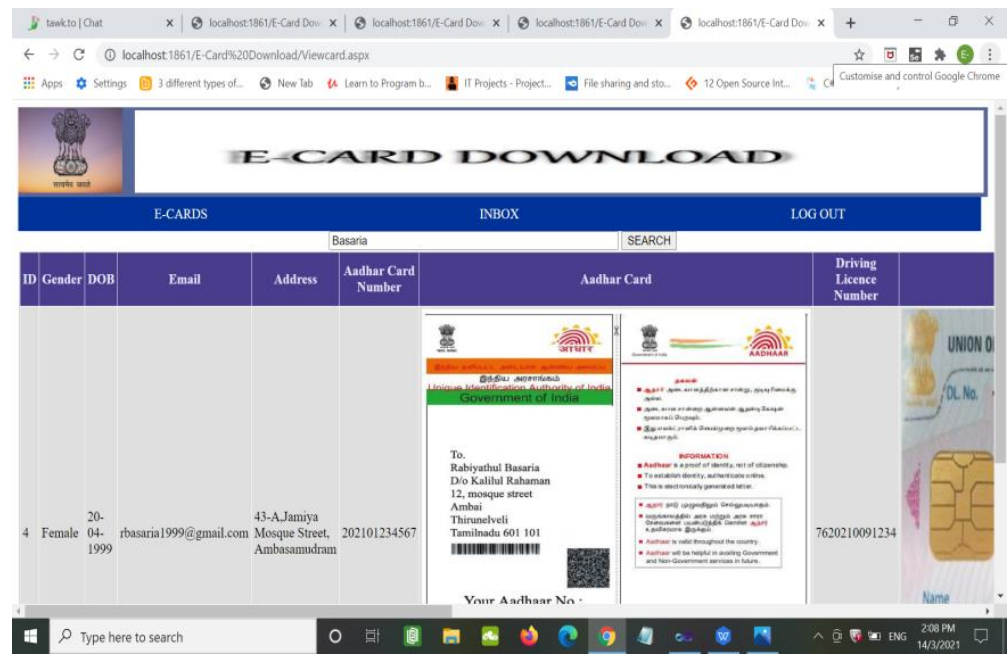

Figure 14. E-card View Page 


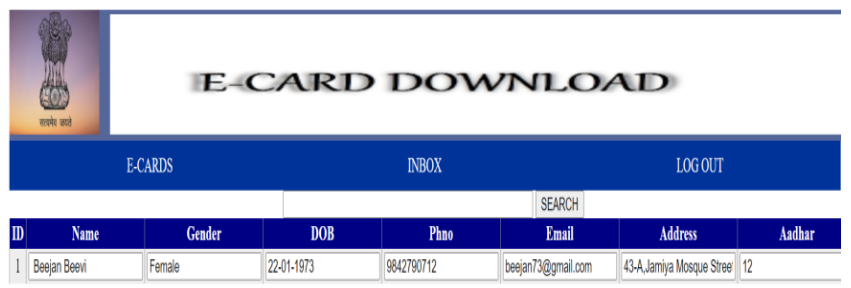

Figure 15. Cards Update Page

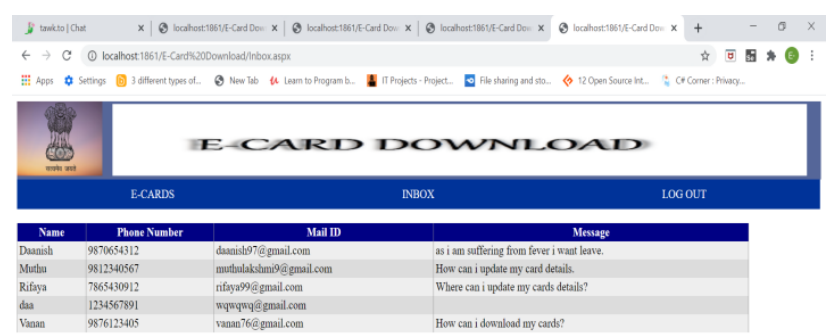

a

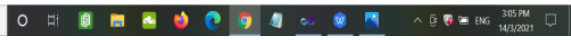

Figure 16. Cards Inbox Page

\section{Performance Analysis}

The existing and proposed system are analyzed. The problem identified in the existing system is user can download the aadhar card document file using otp generation. The framework for authentication is open ended. And user has an hesitation of registering their details because of the security of the web application. Each card has an separate web application to download the cards which leads the user to feel like doing many works. And in these web application there is no direct communication between user and the admin. Nearly, $70 \%$ performance has been increased.

\section{Conclusions}

E-card Download is developed using Asp.net and SQL. This web application provides facility to download cards in a safest manner. It saves time as it allows easy and safest download of cards whenever necessary. Through unique identity number each citizen can download the cards in a safest manner using captcha and otp generation. And can also chat with the admin so that they can get information about the cards through chatbot or mail. 


\section{FUtURE ENHANCEMENT}

In future, first this application can be featured in the improvement of platform to look more interactive. Second this application can add more cards to be download based on future security issues, security can be improved using emerging technologies. Third this application can contains many youtube videos about how to download cards and also the purpose of these cards. Fourth it can involves scanning cards using QR code so that aadhar card, driving licence, ration card and voter id can be scanned and shown in an device as an alternative.

\section{REFERENCES}

[1] S. Ashwin, S .Loganathan, S .Santosh Kumar, P.Sivakumar, "PROTOTYPE OF A FINGERPRINT BASED LICENSING SYSTEM FOR DRIVING” Embedded \& Real-Time Systems PSG College of Technology

[2] Mrs. Padmavathi. R,K.M Mohammed Azeezulla, P. Venkatesh ,Kanchan Kumar Mahato, Nithin G,"Digitalized Aadhar Enabled Ration Distribution Using Smart Card" 2017 2nd IEEE International Conference On Recent Trends in Electronics Information \& Communication Technology (RTEICT), May 19-20, 2017, India

[3] Anshu Prasad, Aparna Ghenge, Sonali Zende, Prof. Sashikala Mishra, Prof. Prashant Gadakh,"Smart Ration Card Using RFID, Biometrics and SMS Gateway" International Conference on Inventive Communication and Computational Technologies (ICICCT 2017)

[4] Dr .M. PALLIKONDA RAJESEKARAN, R.ARTHI, D.BALAJI, P.DANIEL, "Automatic Smart Ration Distribution System for Prevention of Civi Supplies Hoarding In India" 2017 International Conference on Advanced Computing and Communication Systems (ICACCS 2017), Jan. 06 - 07, 2017, Coimbatore, INDIA

[5] Gaikwad Priya B, Sangita Nikumbh, "E - Public distribution system using SMART card and GSM technology " Proceedings of the International Conference on Intelligent Sustainable Systems (ICISS 2017) IEEE Xplore Compliant - Part Number:CFP17M19-ART, ISBN:978-1-5386-1959-9.

[6] Mohamed Mohandes,"A Smart card management and application system", 2010 IEEE International Conference on Progress in Informatics and Computing. Part Number : 10.1109/PIC.2010.5687971

[7] R Padmavathi; K.M Mohammed Azeezulla ; P. Venkatesh; Kanchan Kumar Mahato; G Nithin, "Digitalized Aadhar enabled ration distribution using smart card". $20172^{\text {nd }}$ IEEE International Conference on Recent Trends in Electronics, Information \& Communication Technology (RTEICT). Part Number: 10.1109/RTEICT 20178256670

[8] Ch.Sai Pratap Varma; D.Sumanth Rahul; Jithina jose; B. Keerthi Samhitha; Suja Cherukullapurath Mana "Aadhar Card Verification Base Online Polling" 2020 4th International Conference on Trends in Electronics and Informatics (ICOEI)(48184).

[9] Pooja Shrivastava; Sandeep kumar Agrawal "Unique Identification In Elections through Internet Of Things". Publisher: IEEE 2018 International Conference on Advanced Computation and Telecommunication(ICACT). Bhopal, India

[10] Bhuvanapriya R.; Rozil Banu S.; Sivapriya P.; Kalaiselvi V.K.G. "Smart voting" 2017 2nd International Conference on Computing and Communications Technologies (ICCCT) DOI: 10.1109/ICCCT2.2017.7972261. Chennai India. 
[11]. K. Lakshmi, R. Karthikamani, N. Divya "Aadhar Card based smart e-voting system" International Journal of Engineering and Advanced Technology (IJEAT) ISSN: 2249 - 8958, Volume-8, Issue-2S, December 2018.

[12] Himanshu Agarwal "Online voting system for India based on aadhaar id", N NOVEMBER 2013 DOI:10.1109/ICTKE.2013.6756265 CONFERENCE: 2013 11TH INTERNATIONAL CONFERENCE ON ICT AND KNOWLEDGE ENGINEERING (ICT \& KNOWLEDGE ENGINEERING).

[13] R. Balaji1 , Muhammed Afnas. M. P2 , B. Praveen Kumar3 , V. Varun4 , C. Tamizhvanan5 "Embedded based E-Voting System through Fingerprint and Aadhaar Card Verification ".

[14] B.Madan Mohan Reddy, D. SrihariRFIDBASED BIOMETRIC VOTING MACHINE LINKED TO AADHAAR FOR SAFE AND SECURE VOTING, International Journal of Science, Engineering and Technology Research (IJSETR) Volume 4, Issue 4, April 20

[15] L.Rura, B. Issac and M.K. Halder, ONLINE VOTING VERIFICATION with CRYPTOGRAPHY and STEGANOGRAPHY APPROACHES, Proceedings of 2011 International Conference on Computer Science and Network Technology, Harbin,pp.125-129. 2011 


\section{AuTHORS}

Ms. K. Rabiyathul Basaria doing final year MCA in Francis Xavier Engineering College.

Ms. S. Sujitha working as Assistant Professor in the Department of Computer Applications, Francis Xavier Engineering College. Her area of interest is Wireless Sensor networks

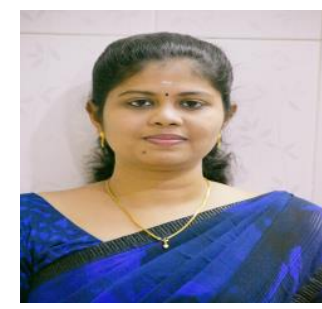

Ms. K. Nambi Natchiar doing first year MCA in Francis Xavier Engineering College

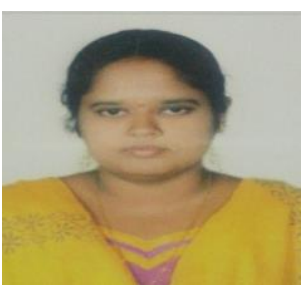

